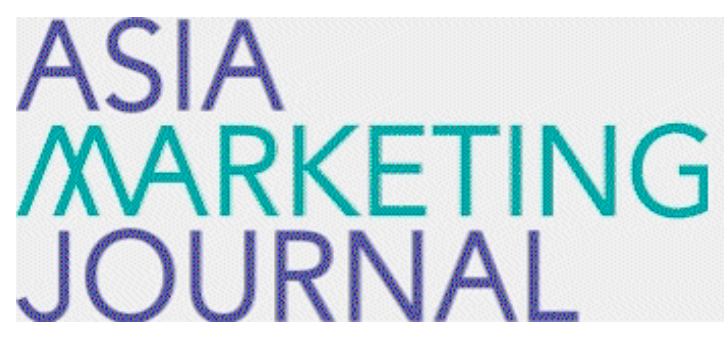

ASIA MARKETING JOURNAL

Volume 15 | Issue 1

Article 2

4-30-2013

\title{
Innovative Marketing Channel in the South Korean Retail Banking Industry
}

Hwan Chung

Sang Young Kim

Chang Jo Yoo

Follow this and additional works at: https://amj.kma.re.kr/journal

Part of the Marketing Commons

\section{Recommended Citation}

Chung, Hwan; Kim, Sang Young; and Yoo, Chang Jo (2013) "Innovative Marketing Channel in the South Korean Retail Banking Industry," Asia Marketing Journal: Vol. 15 : Iss. 1 , Article 2.

Available at: https://doi.org/10.53728/2765-6500.1508

This Article is brought to you for free and open access by Asia Marketing Journal. It has been accepted for inclusion in Asia Marketing Journal by an authorized editor of Asia Marketing Journal. 


\title{
Innovative Marketing Channel in the South Korean Retail Banking Industry: The Case of KB Rockstar*
}

\author{
Hwan Chung** \\ Sang Yong Kim*** \\ Changjo Yoo****
}

To overcome the profitability challenge these days, many global banks are increasingly focusing on cost efficiency through more efficient banking processes, such as online and mobile banking, whereas a number of other banks choose to differentiate their services for retaining and attracting the most valuable customer segment (Deloitte, 2011). While global banks in the retail banking industry are adopting either of these two business models as a strategic choice for their long-term growth, KB Kookmin Bank, one of the leading retail banks in South Korea, has begun to operate 'KB Rockstar' as a strategic channel, particularly designed to target college students in the youth market. The new marketing strategy has resulted in a positive impact on its brand image in customers' perception as well as a drastic increase in the number of youth customers. In this study, we analyze the case of 'KB Rockstar' and summarize the key factors for its success from a marketing perspective. First, 'KB Rockstar' is not simply a good channel strategy, but an innovative marketing strategy that aligns place, product and promotion together in order to create a synergy effect, resulting in the successful implementation of the bank's targeting strategy. Second, the strategy effectively establishes 'KB Rockstar' as a brand targeted to youth customers while also competently strengthening the image of the corporate brand, KB Kookmin Bank. The skillful implementation of organically combined marketing mix strategies has enabled the successful launch of the bank's sub-brand. Third, the strategy considers a retail bank branch as not only the place that makes sales transactions in order to generate short-term profits, but also the place that builds a long-term relationship with customers in order to maximize their lifetime values in the long run.

Key words: Channel strategy, Retail banking, Customer segmentation, Customer lifetime value, KB Rockstar

\footnotetext{
* The authors gratefully acknowledge the financial and data support provided by KB Kookmin Bank. They also thank Ji Hyearn Park for invaluable research assistance.

** Assistant Professor, Chung-Ang University, Korea(hchung@cau,ac.kr)

*** Professor, Korea University. Korea(sangkim@korea.ac.kr). Corresponding Author

***** Professor, Dongguk University, Korea(yoo@dongguk,edu)

$+\quad$ The review of this paper is processed by the special editor. professor Xina Yuan at Xiamen University in China.
} 


\section{Introduction}

As the preference for online banking surged, many retail banks are focusing on cost reduction by transitioning from high-cost channels to low-cost channels in order to maximize profits. However, such expansion of online channels facilitated the easy comparison of products and services among customers and consequently heightened the competition between banks in a highly saturated banking market. Wanting to have a competitive advantage, many retail banks have been gradually shifting their strategic focus from price to service quality as competition intensified in the financial market and various IT technologies developed (Frei et al., 1999). Because it is nearly impossible to satisfy all customers with various needs, retail banks have started to focus on finding the most valuable consumer segment through market segmentation and the acquisition and retention of such a consumer segment rather than targeting the mass consumer through a single brand. Therefore, retail banks have begun to break down the market by age, gender, income level and other criteria, and have started to select a customer segment to target for offering a better-customized service. There are also many instances of banks managing multi-brands in order to target multiple customer segments (Deloitte, 2011).

South Korea's retail banking market is experiencing a similar situation as the global one.
Four major banks and other smaller banks are making much effort to offer better services to customers as well as to enhance their profitability amidst the fierce competition. Furthermore, such efforts have brought about many changes to the banks' channel strategies. Traditionally, the most important factor considered in opening a retail branch was the 'location' because opening a branch in an optimum location enabled banks to attract more customers without special marketing efforts. However, all the recent channel strategies focus on the 'whom' rather than 'where'. It has become increasingly important to understand the major target customers and be able to open a retail branch that provides services that meet the target customers' needs. The PB (Private Banking) Center, which can be found in most banks, is a good example of the focus shift in retail banks channel strategies.

Although the number of face-to-face transactions is decreasing, retail bank branches serve a key role as they maintain intimate relationships with customers in order to enhance brand awareness and gain their trust. Moreover, the accessibility of branches is an important factor that customers consider when choosing a bank: thus, the role of branches is particularly important for banks in order to gain a competitive advantage (Hana Institute of Finance, 2012a). The financial products sold by retail banks possess the characteristics of both a product and a service. The typical characteristics of fi- 
nancial products are easily copied, making it harder for banks to differentiate their own product from those of the competitors (Chun and Lee, 2011). On the other hand, the intangibility of a company's services requires a combination with tangible elements in order to achieve an effective differentiation: with this, the branch can play an important role as the place where customers can experience the differentiated services.

This paper examines KB Kookmin Bank, a South Korean retail bank that achieved successful outcomes through an innovative channel strategy by targeting a specific customer segment. KB Kookmin bank, which experienced a decrease in the number of youth customers, has begun to operate 'KB Rockstar' as a strategic channel, which is particularly designed to target college students in the youth market. The new marketing strategy has resulted in a positive impact on its brand image in customers' perception as well as a drastic increase in the number of youth customers. In this study, we analyze the case of 'KB Rockstar' and summarize the key factors for its success from a marketing perspective. First, 'KB Rockstar' is not simply a good channel strategy, but an innovative marketing strategy that aligns place, product and promotion together in order to create a synergistic effect, resulting in the successful implementation of the bank's targeting strategy. Second, KB Kookmin Bank was able to effectively achieve firm establishment of the $\mathrm{KB}$ Rockstar, the company's new sub-brand, for youth customers, while also effectively strengthening the image of its corporate brand. The skillful implementation of organically combined marketing mix strategies has enabled the successful launch of the bank's sub-brand. Third, the strategy considered a branch of a retail bank as not only the place that makes sales transactions to generate short-term profits, but also the place that builds a long-term relationship with customers in order to maximize their lifetime values in the long run.

\section{Backgrounds for 'KB Rockstar'}

\subsection{KB Kookmin Bank}

KB Kookmin Bank started out in February 1963 as a government-run bank that served the purpose of providing financial convenience to small businesses and people with weak credit strengths and security solvency. After its privatization in 1995, KB Kookmin Bank went through a series of mergers with Daedong Bank and Korea Long Term Credit Bank in 1998, and expanded the bank's size once again as it went through another merger with Korea Housing \& Commercial Bank in 2001. In 2002, the bank was selected by the Financial Times as one of the world's top 500 companies, becoming the first to make the list among the financial institutions in South Korea's domestic 
financial industry.

In September 2008, the KB Financial Group Inc. was officially launched in order to respond to an increased need for comprehensive financial services from customers, the rapid globalization of the financial industry and the changes in the financial environment. Consequently, $\mathrm{KB}$ Kookmin Bank was incorporated into $\mathrm{KB}$ Financial Group as a subsidiary. Aside from KB Kookmin Bank, KB Financial Group owns various subsidiaries including $\mathrm{KB}$ Kookmin Card, KB Investment \& Securities, KB Life Insurance, KB Asset Management, KB Real Estate Trust, KB Investment, KB Credit Information, KB Data Systems, Kookmin Bank Hong Kong Ltd. and Kookmin Bank International Ltd. However, most of the revenues come from KB Kookmin Bank, which serves as the core subsidiary of KB Financial Group (Chun and Lee, 2011). The asset size of KB Financial Group as of 2011 amounts to 240.7 billion U.S. dollars, and the company is included as one of the world's 100 largest banks.

The organizational structure of KB Kookmin Bank consists of 10 groups, 16 divisions and 63 departments: the Marketing Group is in charge of all the tasks directly related to the company's marketing practices. The departments that are directly under the Marketing Group are the Marketing Department and the Customer Satisfaction Department. The Marketing Department is in charge of developing and executing the bank's overall marketing strategies along with the tasks related to CRM (Customer Relationship Management), whereas the Customer Satisfaction Department is in charge of planning and researching customer satisfaction related projects. Moreover, the Product Management Division under the Marketing Group is in charge of developing credit and saving products. In addition to the Marketing Group, the Sales Group is another group that also covers the tasks related to marketing. The Sales Group consists of four departments and plans tasks related to sales activities. The Campus Plaza Business Department under the Sales Group is responsible for planning and management of KB's new channel strategy, 'Rockstar Zone'.

\subsection{KB Kookmin Bank's Current Position in the Korean Banking Industry}

KB Kookmin Bank, with 1,172 Branches at home and abroad, is one of the four largest banks in South Korea. The banks that belong to the Big Four and directly compete with KB are Woori Bank, Shinhan Bank and Hana Bank. By the end of 2011, according to data available from the Financial Supervisory Service in South Korea, Shinhan Bank had 989 branches at home and abroad, Woori Bank had 964 and Hana Bank had 664. Therefore, it is true that KB Kookmin Bank, which has the largest network of branches in Korea, has a competitive advantage in customer accessibility. 
However, despite such advantages, competitors have been growing rapidly and gaining their unique competency via achieving high efficiency and accumulating private banking know-hows, making the competition fiercer and the market more difficult for KB (Chun and Lee, 2011).

In particular, the big problem faced by $\mathrm{KB}$ Kookmin Bank was the continued decrease in the bank's youth customers. By the end of 2007 , the number of youth customers amounted to 4.58 million, making up $17.9 \%$ of the total number of customers: yet, the figures decreased by the end of 2010 to 4.08 million, or $15.7 \%$. A big reason behind such decrease of youth customers was people's perception of $\mathrm{KB}$ as the bank for the elderly generation, preferred by penny-pinching housewives. Moreover, $\mathrm{KB}$ lacked branches compared to its competitors at university campuses, which is the most important channel for connecting with youth customers. By the end of 2010, Woori Bank had 31 branches, Shinhan Bank had 24, Hana Bank had 14 and the Industrial Bank of Korea had 9 branches in university campuses, whereas KB merely had 5 operating branches in university locations.

According to banking officials, $70 \%$ of university students switch their direct deposit account from college to a salary deposit account after employment: hence, it is very important to attract and maintain such customers from their freshman year in college as the continued business from these customers create added value as they make use of even more services and products, such as credit card services and loans in the future (Seo, 1012). Moreover, according to KB Kookmin Bank's research results, the bank incurs a profit loss during the first three years by serving a 19-year-old customer who is just starting college: however. after the three years, the bank experiences a continued increase in profits gained from the customer. By the time this customer reaches age 38 , the point where the bank starts receiving profit that exceeds the bank's average customer profit, this customer brings in almost four times more profit than a brand new 38-yearold customer. Therefore, KB has implemented various marketing efforts to attract youth customers, which have been declining in number since 2007. For example, KB launched a special promotion program, 'KB Campus Star', in order to select college students as campus representatives and have them promote the bank's products and services. The bank also introduced a new product, called 'KB Star*t Account', targeted toward young college students (Chun and Lee, 2011).

Despite such efforts, considering that retail branch accessibility is an important factor in a customer's bank selection, the most important issue that $\mathrm{KB}$ Kookmin Bank faced was to overcome the lack of campus branches in order to attract more college students as customers. In the end, the most effective way to address this issue and transform KB's brand image into a young and hip bank preferred by youth cus- 
tomers was to enter the university campuses. However, there were problems concerning the need to pay hefty donations in order to open campus branches and considerable time was needed in order to wait until universities' contracts with the existing partnered banks expired.

Given these constraints, KB Kookmin Bank launched a strategic channel in January 2011, the 'KB Rockstar', under a brand new concept in order to position itself as a 'young bank for college students'.

\section{Launching the "Rockstar Zone"}

\subsection{The Launch of 'Rockstar Zone' as an Innovative Channel Strategy}

To achieve the strategic goal aforementioned, KB Kookmin Bank first opened the Sookmyung Nunkkot (meaning a snowflake in Korean) Branch in January 2011, and then opened 40 more 'Rockstar Zones' targeting 43 universities nationwide. In choosing the targets, the bank selected universities with more than 10,000 students and also considered other comprehensive factors, such as regional characteristics, surrounding businesses, distance from other universities and competitor presence. The branches were spread out throughout the nation, including 11 Seoul branches, 6 branches in the Seoul metropolitan area and 24 in the Choongcheong.
Yeongnam and Honam provinces: each branch was named after things that the university symbolizes (refer to 〈Table 1〉). For example, the school symbol of Sookmyung Women's University in Seoul is modeled after a snowflake shape in the form of a flower: thus the branch targeted toward Sookmyung Women's University students was named 'Nunkkot', meaning a snowflake in Korean. Yonsei University's school symbol is the eagle and therefore, the Rockstar branch targeting the university was named 'Doksuri', meaning an eagle in Korean. The Rockstar branches were located in the vicinity of the target campuses where there are high traffic and high population density.

Through staffing strategies and the casual atmosphere generated by the employees' attire, KB Kookmin Bank has been making much effort to understand the unique college culture and build solid relationships with its potential customers. Each Rockstar branch consists of five staff members, and because the branches target young students, the staff are in their 20 s and 30 s, dressed in casual attire such as jeans and a shirt rather than formal uniforms. Moreover, KB appoints branch managers who have graduated from the target school and are in their 30s.

\subsection{Unique Space Offering Specialized Services}

"The fresh coffee aroma fills the air during 
$\langle$ Table 1 $\rangle$ Current State of Regional Rockstar Zones in South Korea

\begin{tabular}{|c|c|c|}
\hline Region & Branch Name & $\begin{array}{c}\text { Note } \\
\text { (Target Universities) }\end{array}$ \\
\hline Seoul & $\begin{array}{l}\text { Sookmyung Women's University Nunkkot Branch, Yonsei } \\
\text { University Doksuri Branch, Seoul National University of Science } \\
\text { and Technology Techno Branch. Kyung Hee University Mokryeon } \\
\text { Branch, Kwang Bima Branch, Sungkyunkwan University } \\
\text { Myeongryun Branch, Soongsil University Baekma Branch, Ehwa } \\
\text { Women's University Baekkot Branch, Chung-Ang University } \\
\text { Cheongryong Branch, Hanyang University Saja Branch, Hongik } \\
\text { University Wow Branch }\end{array}$ & $\begin{array}{l}\text { Total } 11 \text { Branches } \\
\text { (11 Universities) }\end{array}$ \\
\hline $\begin{array}{l}\text { Seoul Metropolitan } \\
\text { region }\end{array}$ & $\begin{array}{l}\text { Kyonggi University Hyangnamu Branch, Kyung Hee University } \\
\text { Gukje Branch, Dankook University Black Bear Branch, Suwon } \\
\text { University Chunma Branch, Ajou University Seonguja Branch, } \\
\text { Inha University Biryong Branch }\end{array}$ & $\begin{array}{l}\text { Total } 6 \text { Branches } \\
\text { (6 Universities) }\end{array}$ \\
\hline $\begin{array}{l}\text { Middle-West } \\
\text { region }\end{array}$ & $\begin{array}{l}\text { Namseoul University Baekma Branch, Daejeon University Kkachi } \\
\text { Branch, Baekseok University Doksuri Branch, Chongju University } \\
\text { Uam Branch, Chungnam University Baekma Branch, Chungbuk } \\
\text { University Gaesingol Branch, Hannam University Ojeonggol } \\
\text { Branch, Hoseo University Asan Brach, Rockstar Anseodong } \\
\text { Branch (Hoseo University/Sangmyung University) }\end{array}$ & $\begin{array}{l}\text { Total } 9 \text { Branches } \\
\text { (9 Universities) }\end{array}$ \\
\hline South-East region & $\begin{array}{l}\text { Kyungnam University Hanma Branch, Kyungpook National } \\
\text { University Gamkkot Branch, Gyeongsang National University } \\
\text { Gajwa Branch, Keimyung University Bisa Branch, Daegu } \\
\text { University Biho Branch, Dong-A University Mokryeon Branch, } \\
\text { Dong-Eui University Gayatgol Branch, Pusan National University } \\
\text { Hyowon Branch, Yeungnam University Chunma Branch, } \\
\text { Dookyoung University Motgol Branch (Kyungsung } \\
\text { University/Pukyoung University) }\end{array}$ & $\begin{array}{l}\text { Total } 10 \text { Branches } \\
\text { (10 Universities) }\end{array}$ \\
\hline South-West region & $\begin{array}{l}\text { Chonbuk National University Geonji Branch, Jeonju University } \\
\text { Superstar Branch, Chosun University Baekhak Branch, Chonnam } \\
\text { National University Yongbongtop Branch, Mokpo National } \\
\text { University Dorim Branch }\end{array}$ & $\begin{array}{l}\text { Total } 5 \text { Branches } \\
\text { (5 Universities) }\end{array}$ \\
\hline
\end{tabular}

the morning hours. The Central Hall is filled with university students who showed up after hearing the news about a Recruiting Seminar. The seminar room in one corner is hosting a series of students' final rehearsals for their group project presentations. At the mini café on the opposite of the seminar room, students are browsing the internet with a tablet PC while sipping coffee. This is a typical scene at 'Rockstar Zone', a retail branch launched in universities by KB Kookmin Bank."

- Kang (2011), The Korea Economic Daily. 
〈Figure 1> Internal View of a Rockstar Branch

(Sookmyung Women's University Nunkkot Branch)

Internal View of Café-style Branches

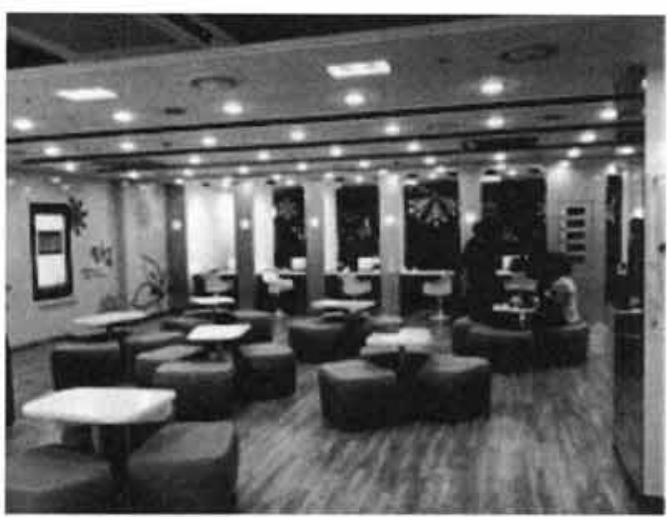

Media Wall

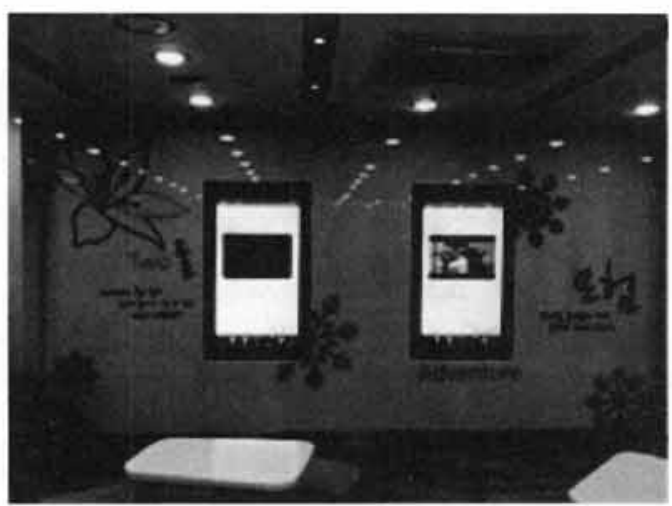

Considering that a typical bank's retail branch had difficulties attracting college students, KB Kookmin Bank began to operate a customerfriendly branch that combines the standard branch with youth-friendly offerings preferred by students. Each Rockstar branch consists of a 'Bank Zone' for standard bank operations and services and a 'Fun \& Community Zone'. In particular, the latter is receiving much positive feedback from college students. Moreover,
Multichannel Space

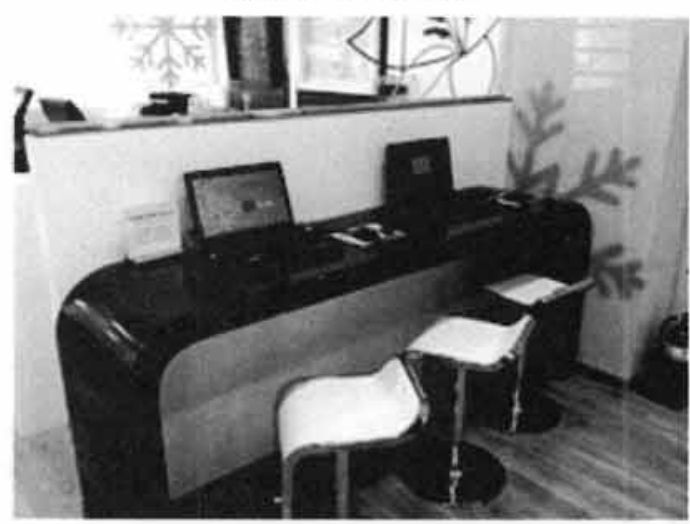

Seminar Room

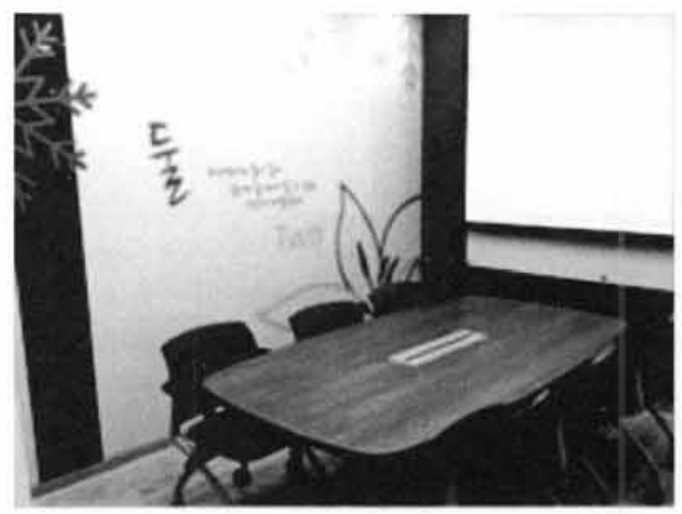

the interior of Rockstar branches reflect each university's symbol and colors, creating a more intimate atmosphere for students (refer to $\langle$ Figure 1〉).

In the 'Bank Zone', the branch offers standard financial services like typical bank branches, and also offers financial counseling customized toward college students, encouraging students to develop an early interest in personal finances. Furthermore, the bank offers products 
that are particularly created for students, which will be discussed further in section 4.1. In the early stages, the branches did not offer Bancassurance ${ }^{1 !}$ or loans: however, the branches are now expanding their operations and services taking account of customer needs.

In the 'Fun \& Community Zone', there is a seminar room, a media wall, an internet and $\mathrm{Wi}-\mathrm{Fi}$ zone, and a multi-channel space. The seminar room is used for hosting various events, including job seminars, finance courses and other courses that reflect the needs and interests of college students, and also offers the branch's own small-scale events. Moreover, students can rent out the room and iPads for club meetings and team project presentation rehearsals. The media wall is in the form of a touch screen and offers various contents, including a brochure of the bank's product offerings, a search feature listing all merchants that offer special card discounts in partnership with the bank, photo services, and games among others. The multichannel space enables customers to freely use PCs and iPads, and the ten branches in Seoul boasts an installation of 'KB Rockstar Sam's Café' in partnership with

〈Figure 2〉 Main Features of Rockstar Branches

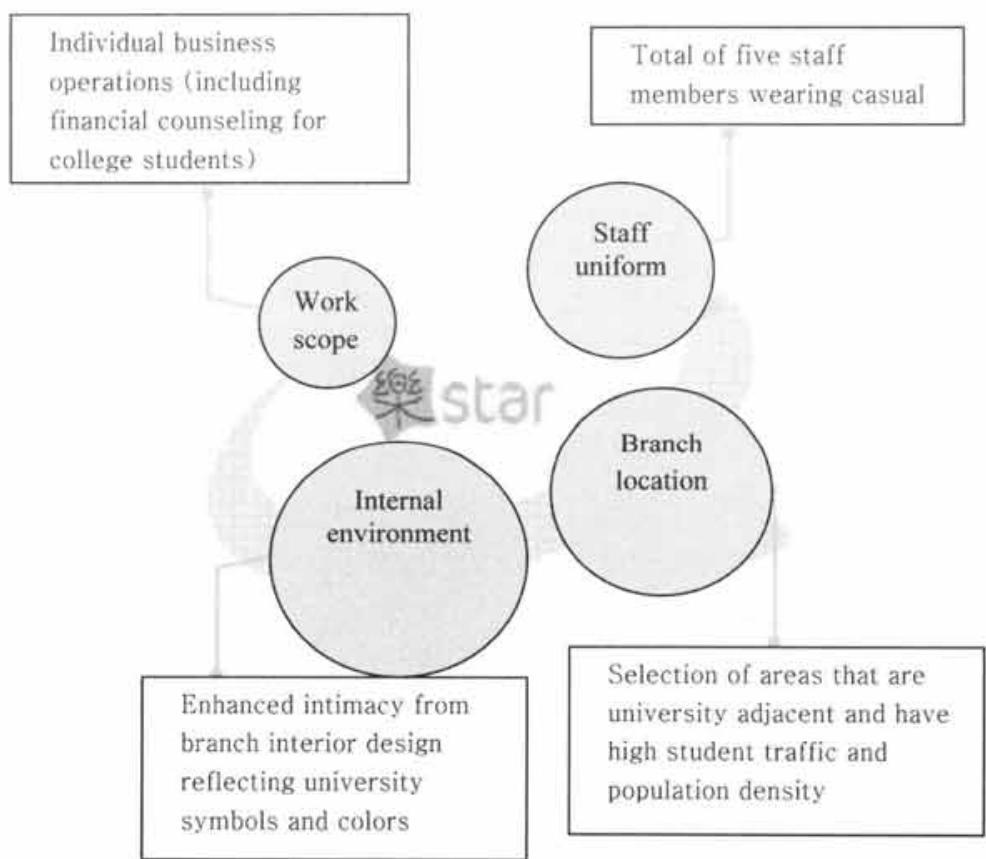

1) Bancassurance is the offering of insurance products from banks, operating like a retail branch of insurance companies. Through this offering, the bank can provide comprehensive financial services, which include banking, securities business and insurance (MK Business News 2013). 
Samsung Electronics, which enables customers to test out the latest IT products.

\section{Integrated Marketing Mix Strategy}

In order to meet the demands of the target market more effectively, a marketing mix strategy for each variable has to be formulated in such a way that each would complement or reinforce the others in order to develop synergy (Rosenbloom 2011, p.176). To firmly establish the 'Rockstar Zone' as a brand for youth customers rather than simply being recognized as a youth-friendly retail branch, KB Kookmin Bank made numerous efforts by developing customized products sold only at the 'Rockstar Zone' and also launched various sales promotion events geared toward university students.

\subsection{Product}

In 2008, KB had already launched the youthtargeted 'KB Star*t' account, which offered a premium interest rate up to a certain deposit amount. Building upon such experience, the bank developed customized product offerings that were only offered at the 'Rockstar Zone'. The 'KB Rockstar Account' is offered to individuals aged 18 to 28 , and the account can be opened only at Rockstar branches. The 'KB
Rockstar Account' enables users to freely deposit and withdraw from the account, and there is no minimum amount required to open the account. 'KB Rockstar Account' users are exempt from automatic transfer fees to different banks and ATM fees if they have a record of automatic payments, installment savings, KB Check Card payments, student loans or between-account automatic transfers through the account. Moreover. the account holder can personally select the account number that they can easily remember, and are also eligible for a premium interest rate of $4 \%$ for deposits up to $1,000,000$ South Korean won (about US $\$ 1,000$ ). The standard bank interest rate applies to any amount exceeding the 1,000,000 won amount. While other banks typically offer premium interest rates for deposit amounts that exceed a certain amount, this offering was impractical and ineffective for youth customers whose deposit amounts are usually under 1,000,000 won. Thus, KB Kookmin Bank attempted a contrarian strategy, where the bank offered premium interest rates on demand deposits that have low interest rate sensitivity (Chun and Lee, 2011).

The 'Rockstar Check Card', which is another product only offered at the 'Rockstar Zone', is also geared for customers aged 18 to 28 . Youth customers can apply for and receive the card only at the Rockstar branches. The card offers various discount services, such as cellphone bill automatic payment discounts, public transit discounts, movie theater and theme park dis- 
counts, restaurant discounts, convenience store discounts and bookstore discounts, which are effectively tailored to youth customers. Moreover, the 'Rockstar Installment Savings' is offered to individuals over 18 years old, and customers can only join the installments at the Rockstar Zone. The customer can select the contract period among a monthly selection starting from 6 months up to 24 months. The initial enrollment amount is any amount larger than 10,000 won, and the customer can freely deposit amounts up to $3,000,000$ won per quarter. The interest rates differ depending on the contract period: however, there are additional interest rates available for students who have received a scholarship or obtained a higher score on nationally certified foreign language tests, such as TOEIC, enabling a maximum interest rate of $4.3 \%$ per year for individuals on a 24 -month contract. Furthermore, KB Kookmin Bank attracted customers visiting the 'Rockstar Zone' to sign up for installment savings by offering a $0.1 \%$ additional prime interest rate for additionally signing up for a KB Rockstar Card or opening a Rockstar Account. During the initial stages of launching, KB only offered customized 'Rockstar Zone' products; however, it has also started to offer additional products available at other regular branches.

\subsection{Promotion}

\subsubsection{Implementation of Various Culture Marketing Strategies}

To differentiate itself from other competing banks and to strengthen its unique youthfriendly Rockstar brand image, KB Kookmin Bank conducted various cultural marketing practices favored by university students. In addition to informational events, such as recruitment events and finance seminars, $\mathrm{KB}$ also organized cultural events including indie band concerts, chamber concerts, Rockstar Culture Festival and rap competitions. By hosting several of these events in the 'Rockstar Zone', the bank was able to achieve effective promotion of branches and raise awareness of the location as a comprehensive culture zone. Furthermore, the bank increased its customer satisfaction by sharing the university culture and offering bi-directional culture events that were differentiated from the typically unidirectional promotional events.

For example. KB selected the 'Rockstar Zone' to host a chamber concert based on regional distribution, existence of a university music department and available space: furthermore, it also selected performance teams to target university students and played pop, K-pop, movie soundtracks and other various genres of music. The bank used the catch phrase "Bank meets culture" in order to raise awareness of the Rockstar brand as a comprehensive culture zone 
where information and culture coexist. By enabling university students to directly participate in the performances, the bank was able to receive highly favorable responses from the students (refer to 〈Figure 3$\rangle$ ). In addition, the bank also hosted the Rockstar Culture Festival, consisting of small-scale sports events and arts performance competitions, where employees at the KB 'Rockstar Zone' and the students can participate together and form a sense of intimacy and connectedness.

Besides the various cultural events, $\mathrm{KB}$ also launched the 'Rockstar Challenge: Overseas Backpacking Trip' through which the bank offered opportunities for university students to travel to Mongolia, Nepal, New Zealand, Kenya, Eastern Europe and the Balkans, as well as to understand the diverse people and their ways of life and enhance students predilection for challenges. $\mathrm{KB}$ also strengthened the promotional effect of the Rockstar brand by hosting raffle events for 'Rockstar Account' and 'Rockstar
Check Card" customers to win tickets for the highly popular professional league baseball games. Additionally, 'Rockstar Zone' also gave away invitations to external cultural events, such as "African Arts Festival" and a musical named "Special Letter," offering students various opportunities of cultural experiences. The musical invitation event, in particular, was targeted toward opinion leaders of the universities' student councils, clubs and unions, maximizing the promotional effect of the event held.

\subsubsection{Dedicated Blog Operations \& Marketing Efforts Utilizing Social Networking Services}

With the rise of social media usage around the world and the increased number of cases where global financial companies achieved successful results utilizing social media, there is a rising awareness for the need to actively utilize social media in order to attract youth custom-

\section{〈Figure 3〉 Various Rockstar Cultural Events}

Rockstar Culture Festival

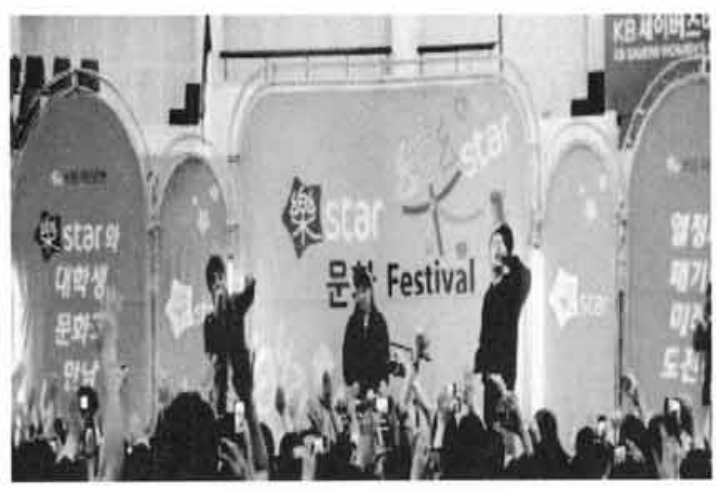

Rockstar Chamber Concert

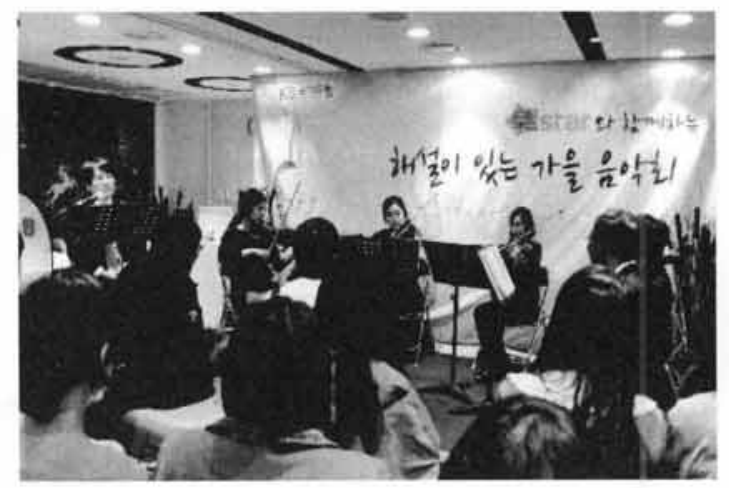


ers among many global financial companies (Hana Institute of Finance, 2012c). KB Kookmin Bank correspondingly launched a dedicated blog for Rockstar to effectively promote and strengthen the Rockstar brand image, and also conducted various marketing practices through social networking services, such as Twitter and Facebook.

First, KB launched the 'Rockstar Social Blog' as a Rockstar dedicated blog to actively conduct Social Networking Service (SNS) marketing practices befitting the Rockstar brand. Customers wanting to use the blog could log-in using a Facebook account or through an internal sign up system: the blog has been continuously offering various contents that are popular among the youth group in connection with Facebook. The blog offers its users with chances to engage in individual activities through the 'my page' feature, and each branch has its own page, enabling interactive communication between the bank and the customers. University student customers can reserve the Rockstar Zone' seminar room through the blog and also participate in various events.

Also, KB developed the 'Rockstar application' in response to the current trend of active smartphone engagement among the youth. Through this application, university students can easily find a Rockstar branch nearest to their current location, reserve a seminar room and receive information about financial services as well as utilize the Rockstar blog.
Lastly, KB Kookmin Bank is currently operating a Twitter and Facebook account for Rockstar representatives and every Rockstar branch. Through such utilization of social networking services, $\mathrm{KB}$ strives to promote its sales promotion activities by means of word-of-mouth. Also, in offering real time responses to the customers and sharing contents concerning matters outside of typical bank operations, the bank was able to establish a special connection and intimacy with its youth customers.

\subsubsection{Joint Marketing Efforts in Partnership with External Institutions}

To strengthen the Rockstar brand image, KB Kookmin Bank conducted co-marketing efforts with external institutions. First, KB collaborated with Samsung Electronics in marketing efforts to maximize the synergistic effects derived from the partnership between No. 1 brands in the finance industry and the electronics industry. As mentioned previously, $\mathrm{KB}$ opened the ' $\mathrm{KB}$ Rockstar Sam's Café' inside the Rockstar Zone and enabled customers to use and test out the latest Samsung Electronics products. Whenever Samsung launched a new IT device, the company continuously sponsored its products for $\mathrm{KB}$ to display in the Rockstar Zone, and Samsung also sponsored KB's promotional events by providing its own products. Utilizing such sponsorship from Samsung. KB Kookmin Bank conducted various marketing efforts, such as cam- 
era-lending services for students during the university entrance and graduation seasons. During exam periods, the Rockstar Zone also offered students free printing with Samsung printers.

In April 2012, KB Kookmin Bank formed a marketing partnership with Uhak.com, Korea's no. 1 brand among the study abroad agencies, and actively sought ways to meet youth customers' needs through offering services related to study abroad, which is one of the primary interests of Korean university students. Under the specific partnership agreements, the professionals from Uhak.com can visit different Rockstar branches and promote various study abroad information sessions, and the agency can display its pamphlets at the Rockstar Zone, obtaining an opportunity to utilize the space as a sales promotion channel, Moreover, KB gained sponsorship from Uhak.com and offered free study abroad packages as a prize for its promotional events, and also increased financial transactions between the two companies to maintain favorable partnership. Also, when an Uhak.com professional hosts information sessions at the Rockstar Zone, Rockstar products are promoted during the session, providing a sales opportunity for KB through the partnership

\subsubsection{Social Contribution Activities through University Student Support}

As a financial company, KB Kookmin Bank actively utilized the Rockstar brand in order to offer various financial benefits to university students. First, the company hired up to six university students as part time workers for the Rockstar Zone. By hiring from the university. the company aimed to increase the connectedness with the target school and also aimed to understand the students' needs and increase customer satisfaction for youth customers through actively communicating with the students. Furthermore, the company also selected two students from part-time employed students after considering their employment period, employee evaluation and family finances, and awarded these students with a scholarship of 1.5 million won (about US \$ 1.500) per person, aiding the students' tuition payments.

Second, KB Kookmin Bank aimed to enable students to experience the financial culture by providing education in Economics as well as opportunities to participate in financial investments. An example of such efforts is the Rockstar Campus Stock Festival', a mock stock investment competition. A total of 10,139 university students participated in this competition, and a total of 220 students, all of the top five investors from each participating school, made it to the finals. Among the finalists, the top fifteen students were selected and were awarded scholarships.

Such social contribution activities derive its significance from the strengthening of the Rockstar brand's positive image and securing young collegiate customers who will contribute to the future growth engine of the company. 


\section{Marketing Performance}

The new marketing strategy has enabled $\mathrm{KB}$ Kookmin Bank to lock in the future customer base and renew their brand image. First of all, KB's Rockstar Zone brought 236 thousand young customers in 2011. This exceeded the bank's original target by 2,000 customers, as illustrated in Figure 4. Figure 5 shows that the annual growth of youth customers was $-5 \%$ since 2005. In addition, the youth population in Korea has decreased over the years. However, Rockstar Zone has reversed the decreasing trend of CIF (Customer Information File) new youth customer numbers, as indicated in Figure 5 , and the bank had 365 thousand youth customers as of June 2012. This was a tremendous success considering that the number of students enrolled at targeted universities was about 612 thousand.

〈Figure 4〉 Rockstar Customer Population

Unit: Thousand 236

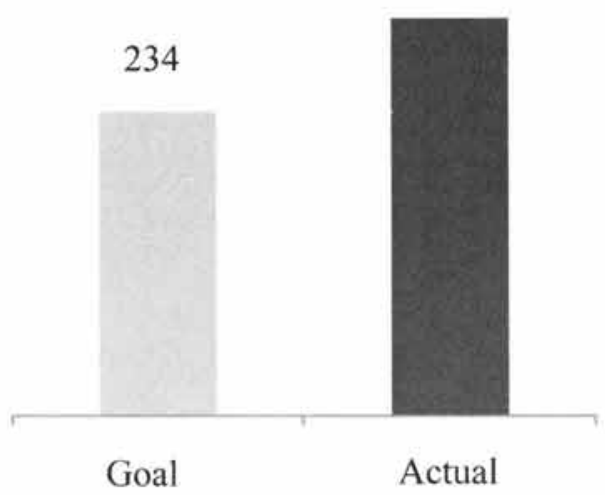

As a result, according to the market research conducted in 2011, customers between the ages of 20-29 have increased their banking transactions with $\mathrm{KB}$ by $0.4 \%$ in 2011 compared to 2010 (refer to 〈Table 2〉). However, the overall transaction count has decreased by $0.6 \%$ in the same time span and all the other segments had decreased transactions, averaging $0.3-0.5 \%$.

$\langle$ Figure 5$\rangle$ Number of CIF New Youth Customers for the Last 8 Years

Unit: Thousand

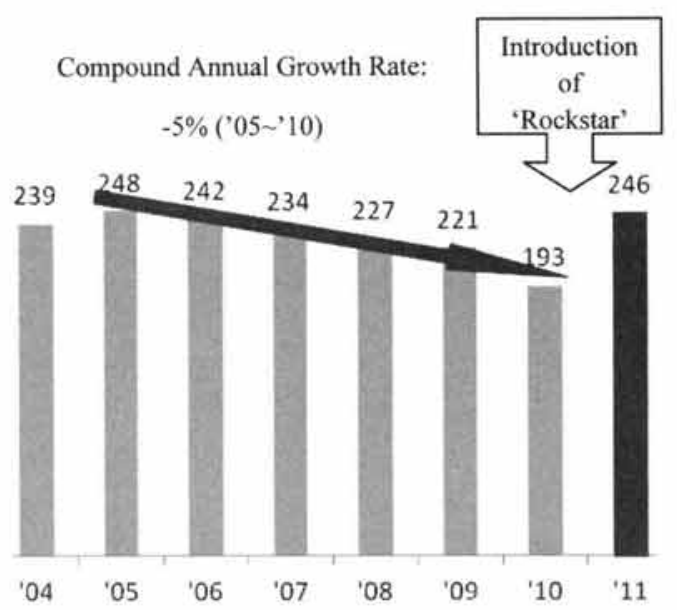

Second, Rockstar has contributed in renewing the image of KB Kookmin Bank into a younger brand. According to KB's internal research conducted in 2011, the bank's image has transformed into a young generation's bank from a bank that was preferred by penny-pinching housewives. As portrayed in Figure 6, KB has surpassed, in preference, to every other banks who were traditionally the major player in university campuses: KB Kookmin Bank (77.2\%), 
Shinhan (63.6\%) and Woori(55.6\%). $81.5 \%$ of college students and $74.3 \%$ of the newly hired showed preference for KB Kookmin Bank. Moreover, $62.5 \%$ of the customers who visited the new branch showed satisfaction and $77.1 \%$ agreed that Rockstar Zone has contributed in enhancing the image of KB. Diverse marketing and cultural experiences provided at Rockstar Zones were definitely the success factor. However, as shown in Figure 6, the lower preference demonstrated by the newly hires compared with that of the college students still implies that $\mathrm{KB}$ would have to maintain the good relationship built with college students long after they graduate.

〈Table 2〉 KB's Transaction by Age

\begin{tabular}{|c|c|c|c|}
\hline Age & $' 10$ & $' 11$ & $+/-$ \\
\hline $20 \sim 29$ & $23.5 \%$ & $23.9 \%$ & $+0.4 \%$ \\
\hline $30 \sim 39$ & $24.8 \%$ & $24.5 \%$ & $-0.3 \%$ \\
\hline $40 \sim 49$ & $23.8 \%$ & $23.3 \%$ & $-0.5 \%$ \\
\hline $50 \sim 59$ & $24.4 \%$ & $24.1 \%$ & $-0.3 \%$ \\
\hline All & $57.2 \%$ & $56.6 \%$ & $-0.6 \%$ \\
\hline
\end{tabular}

Another external achievement is the '2012 The Proud Customer Value Excellence Award awarded by Korean Management Association Consulting (KMAC). Out of 264 candidates based on 24 fields, including innovativeness, value diffusion and customer performance, 'Rockstar' has been selected. This proves that KB's efforts for differentiating the brand image through customer-oriented marketing strategies were successful,

\section{Conclusion}

\subsection{Success Factors}

In order for commercial banks to thrive in the competitive financial market, they need to provide unique products and services, meeting customer needs through the right mix of faceto-face and non-face-to-face transactions. Also, they should be able to attract target customers

〈Figure 6〉 Youth Customers' Preference Survey

\begin{tabular}{|c|c|c|c|}
\hline & [Youth Total] & [College Students] & [Newly Hired] \\
\hline $\mathrm{KB}$ & $77.2 \%$ & $81.5 \%$ & $74.3 \%$ \\
\hline Shinhan Bank & $63.6 \%$ & $65.5 \%$ & $62.3 \%$ \\
\hline Woori Bank & $55.6 \%$ & $54.5 \%$ & $55.3 \%$ \\
\hline Hana Bank & $25.6 \%$ & $29.5 \%$ & $23.0 \%$ \\
\hline
\end{tabular}


by establishing their own unique brand image (Hana Institute of Finance, 2012b). The public's interest in corporate social responsibility is growing and $\mathrm{KB}$ Kookmin Bank's traditional image of being the bank for commoners would be potentially helpful for long-term profitability. However, that traditional image has been somewhat negative in marketing to the young generation, which resulted in a decrease in youth customers. Therefore, in order to turn around this trend, $\mathrm{KB}$ has come up with an innovative distribution channel called "Rockstar Zone" and started capturing the young generation for the bank's future growth. This strategy has proved successful by turning the bank's image into a more youthful and modern bank. The key success factors of such an innovative marketing strategy can be summarized as follows.

First, Rockstar is not merely a good channel strategy, but an innovative marketing mix strategy that aligns place, product and promotion together in order to create a synergy effect. resulting in the successful implementation of the bank's targeting strategy. KB Kookmin Bank did not plan the Rockstar Zone to be just a café or a place for trendy gathering among young customers, but engineered the branch to be a place to provide services for meeting various needs from their everyday life as well as their financial needs. To achieve these goals, the bank has placed the university's alumni employee at the Rockstar branch in order to provide financial consulting and services. Moreover. the bank has developed products geared toward college students' needs as well as promoting various events reflecting their culture. Thus, the branch has not been just a banking facility but a place for creating emotional connections with customers. A similar case would be the Apple store. Despite the industry's negative forecasts, the Apple store was a successful launch and their effort to overcome the weak distribution channel. Apple did not focus on maximizing sales while building these stores throughout the world. They focused on giving potential customers the "Apple experience" and tried to extend an emotional connection to their customers (Stross, 2007). The Genius bar was installed in the store and was run by experts who possess in-depth knowledge of the products: moreover, their pay was fixed rather than depending on their sales commission. These efforts led to a credible image of Apple products as well as Apple employees and as a result, customers felt at ease learning about Apple.

Second, KB Kookmin Bank uses a new brand name "Rockstar" rather than using its corporate brand. Rockstar Zone, as a branch, functions as a place for customers to experience the new sub-brand of $\mathrm{KB}$, which, combined with other marketing mix variables, eventually leads young customers to become familiar with the new "young" KB Kookmin Bank. This enables the bank to manage their customers in separate segments and pursue various opportunities 
utilizing the different channels. KB's approach to the youth generation using the new brand is successful in terms of effective segmentation and future strategy.

Lastly. KB Kookmin Bank does not look at the Rockstar Zone as another distribution channel for generating more transactions focusing on short-term profit maximization. Rockstar Zone is seen as more of a long-term investment that will establish good customer relationships by focusing on building the brand loyalty and introducing their culture to potential customers. Current marketing programs of other Korean financial institutions are more performance-based, short-term programs that emphasize the generation of transactions. The reason for this is that most marketing divisions are originally from the sales departments that manage sales activity and promotions (Chun, 2010). On the other hand, KB Kookmin Bank's Rockstar strategy focuses on longer period of customer's lifetime and maximizes the value in lifetime support. Although the Rockstar Zone may not generate high profits because it targets college students, KB's exploration in innovative marketing, such as Rockstar strategy, was developed considering the long-term profits expected from maximizing the customer lifetime value.

\subsection{Future Challenges}

KB Kookmin Bank oversees 41 Rockstar Zones, targeting 43 universities in Korea. In terms of profitability, the bank has earned 489 billion won (about US \$ 470 million) worth of deposit account balance as of December 2012 and attracted 430 thousand people. However, it is tough to gain high profit by targeting college students with products such as debit cards, checking and savings account. Also, the overhead cost for maintaining 41 branches, each of which has five employees, is not something to be overlooked. Even though this is a long-term investment not to be compared with other normal branches, it would not be easy to maintain Rockstar branches for a long time if it cannot prove the long-term profitability. Therefore, further research is needed in order to retain those college students, acquired by Rockstar branches, through various stages of their lives in their 30 s and 40 s after college graduation.

The most important thing in achieving this goal is to keep track records of acquired youth customers. The bank needs to quantify their profitability with the track records and come up with metrics to measure the lifetime revenue of the customers. By doing so, the bank will be able to figure out what to do for maintaining a long-term relationship with them more effectively and efficiently as well as to prove the success of Rockstar strategy.

KB Kookmin Bank also needs to work hard to maintain the first mover advantage achieved by being the first bank introducing a new brand to target the youth segment. Due to remarkable success of the Rockstar Zone, other banks, 
which have had a skeptical attitude, started to benchmark the project. For instance, Shinhan Bank has opened "S20 Smart Zone" around the campus area and Woori Bank has launched a smart branch called "Seumusal (meaning 20s in Korean) Woori" (Ha 2012). Shinhan Bank is utilizing the brand "S20" to market S20 checking/savings account and host "S20 Youth Festival" in order to compete aggressively with KB's Rockstar Zone. KB needs to react fast to such upcoming rivals and keep their advantage by coming up with differentiated strategies continuously.

〈Received March 19. 2013〉

〈Revised April 11. 2013〉

〈Accepted April 12, 2013〉

\section{References}

Chun, Sung Yong (2010), “An Exploratory Study on Marketing of Financial Services Companies in Korea," Asia Marketing Journal, 12 (2), 111-133. and Dong-Jin Lee (2011), "Marketing Strategies for Korean Bank Customers: The Case of the KB Star*t Savings Account," KBR, 15 (3), 1-23.

Deloitte (2011), “The fourth dimension: Building customer-centric business models in retail banking," A Deloitte Research Study, March 2011.
Frei, Frances X., Ravi Kalakota, Andrew J. Leone, and Leslie M. Marx (1999), "Process Variation as a Determinant of Bank Performance: Evidence from the Retail Banking Study," Management Science, 45, 9, 12101220 .

Ha, Nam Hyeon (2012), "Commercial Banks, 'Smart Competition' among university campuses, series of 'Smart Branch' launches," The Herald Business , Dec. 12 2012.

Hana Institute of Finance (2012)a, "Global Banks and their Endless Transformations for the Customers," Weekly Hana Financial Focus, 2 (29), 12-13. (2012)b, “Banks' Successful Customer Acquisition Strategies," Weekly Hana Financial Focus, 2 (43), 10-11. (2012)c, "Increase of Social Media Utilization Among Financial Companies," Weekly Hana Financial Focus, 2 (46), 10-11.

Kang, Dong Gyun (2011), “From Recruiting Events to Culture Seminars.'Kookmin Bank Gets Young with 'Rockstar Zone," The Korea Economic Daily, Sep. 26 2011.

MK Business News (2013), "Bancassurance," (accessed April 11, 2013), [available at http://find.mk.co.kr/].

Rosenbloom, Bert (2011), Marketing Channels A Management View, OH: South-Wetern Cengage Learning.

Seo, Mi Sun (2012), "From Fee Benefits to Additional Interest Rates $\cdots$ Bank Accounts 
Customized for University Students Attracts Attention," Seoul Finance, Nov. 28 $8^{\text {th }}, 2012$.
Stross, Randall (2007), "Apple's Lesson for Sony's Stores: Just Connect," New York Times, May $27^{\text {th }}, 2007$. 